\title{
ВОСПИТАНИЕ МОЛОДЕЖИ
}

УДК 371.13

DOI: $10.23951 / 2307-6127-2017-4-75-80$

\section{НАСТАВНИЧЕСТВО: МОДНЫЙ ТРЕНД ИЛИ ОСОЗНАННАЯ НЕОБХОДИМОСТЬ?}

\author{
И. О. Кириллова \\ МБОУ «СОШ № 198», Северск
}

Рассмотрена необходимость организации работы учителей-наставников с молодыми специалистами и малоопытными учителями: привлечение квалифицированных кадров, передача корпоративной культуры, социализация в профессиональном сообществе. Определено понятие наставничества в образовательной организации. Описана мотивация опытных учителей к занятиям наставнической деятельностью: признание авторитета, расширение полномочий, финансовая поддержка. Анализ анкетирования педагогов-наставников позволил выявить трудности учителей, не имевших наставников в начале трудовой деятельности, недостаточную сформированность компетенций наставника, необходимость специальной подготовки для работы наставником, обучения, сопровождения и оценки. Определены ключевые показатели успешности в профессии: общение с детьми, общественная значимость профессии; первые годы работы являются значимым периодом для становления и закрепления в профессии; коммуникативность, мобильность и обучаемость; отсутствие наставника - одна из важных причин возникновения профессиональных затруднений. Описаны направления развития и разнообразия форм наставнической деятельности в школе.

Ключевые слова: наставник, молодой учитель, выбор профессии, профессиональное становление, показатели успешности, наставнические группь, сотрудничество, сопровождение, взаимообучение.

Образовательные учреждения Томской области испытывают постоянную нехватку специалистов педагогического профиля. Дефицит кадров в образовательных учреждениях Томской области вызвал необходимость целевого направления выпускников школ в педагогический вуз, создание специальных условий для их привлечения в сады и школы, для закрепляемости привлеченных молодых педагогов в образовательном учреждении. В настоящее время в различных муниципалитетах Томской области доля молодых и малоопытных педагогов составляет от 9 до $21 \%$ [1]. Одним из условий, позволяющих оказывать действенную помощь молодому педагогу, стало возрождение традиций наставничества.

Трактовки термина «наставничество» в литературе, как правило, описывают особенности конкретной ситуации и сложившихся взаимоотношений между наставником и его подопечным. В рамках данной статьи под наставничеством следует понимать индивидуальную работу с вновь принятыми работниками по введению в профессию и профессиональному развитию, социокультурной адаптации в коллективе [2]. Наставник - это опытный педагог, который не только передает знания и опыт, но и помогает выстроить индивидуальную программу собственного развития, наладить взаимоотношения в классе и коллективе.

Для чего опытный педагог берет на себя эту дополнительную и сложную работу? Назначение педагога наставником является признаком его авторитетности в коллективе, доверия 
администрации. Наставничество - вариант горизонтального развития карьеры учителя-наставника, ему передаются полномочия по взращиванию молодых педагогических кадров, он осуществляет неформальное управление молодыми коллегами, реализуя преемственность знаний, культуры и традиций образовательной организации. Сегодня наставничество поддерживается на уровне образовательной организации, муниципалитета, региона выплатой стипендии Губернатора Томской области лучшим учителям образовательных организаций, проводятся конкурсы мастерства молодых учителей, наставников, совместные конкурсы наставников и наставляемых, опыт наставников представляется Информационно-методическим центром, Томским государственным педагогическим университетом (ТГПУ), Региональным центром развития образования, на электронных ресурсах.

Наставничество, являясь мировой тенденцией во всех сферах, становится трендом современного образования: организации привлекают квалифицированные кадры, обеспечивая с помощью наставничества передачу корпоративной культуры, успешную социализацию в профессиональном сообществе, проектирование карьеры и реализацию проекта с постоянным сопровождением молодого педагога более опытным, преемственность поколений [3]. Наставник для успешного выполнения своих обязанностей должен обладать целым рядом необходимых компетенций, он также нуждается в специальном обучении, а его деятельность - в сопровождении и оценке. Для составления полного портрета современного педагога-наставника, определения его сильных сторон, проблем и необходимых личностных качеств эмпирических исследований проведено недостаточно.

В феврале и апреле 2017 г. в ТГПУ прошли научно-методические семинары по теме «Наставничество как деятельностное сопровождение молодого педагога в школе и ДОУ», собравшие педагогов-наставников из разных муниципалитетов Томской области, победителей приоритетного национального проекта «Образование», стипендиатов Губернатора Томской области. С целью выявления факторов, оказавших влияние на выбор ими профессии и профессиональное становление, было проведено анкетирование участников семинара. В анкетировании приняли участие 24 человека в возрасте от 30 до 60 лет. 92 \% сегодняшних учителей - наставников молодых педагогов отмечают, что их выбор был обусловлен желанием, зародившимся в детстве или юношестве во многом благодаря примеру обучавших их педагогов, а у 8 \% - низким профессиональным уровнем и негативными чертами характера их школьных учителей (желание быть лучшим педагогом в сравнении с имевшимся).

В большей степени на выбор профессии учителя повлияла возможность общаться с детьми (54 \%), желание заниматься педагогикой (42 \%), важность и общественная значимость профессии учителя (33 \%). Наставничество в рассматриваемом контексте позволяет реализовывать названные позиции: общение с младшим по возрасту коллегой, педагогическая деятельность по его обучению, развитию и социализации в коллективе, признание заслуг в профессиональном сообществе - назначение наставником [4].

Одинаковое число респондентов (29 \%) указали, что их выбор был окончательным и ничто не могло на него повлиять и что выбор профессии учителя произошел по случайному стечению обстоятельств. С утверждением, что «подлинной школой для профессионального становления являются первые годы самостоятельной работы», согласились 84 \% сегодняшних учителей-наставников. И это же число анкетируемых указали, что первые годы самостоятельной работы подтвердили его правильность. При этом у 42 \% из них не было официально закрепленного педагога-наставника, значит, они не были в роли наставляемых, у них нет личного опыта взаимодействия с наставником, сложившейся модели взаимодействия, они нуждаются в формировании и развитии компетенций менеджмента, саморазвития, социокультурной адаптации, коммуникативно-педагогических компетенций. 
Вспоминая начало трудовой деятельности, 84 \% опрошенных отмечают, что сразу установились хорошие отношения с учениками (таким образом, мотивация к общению с детьми возросла у $30 \%$ респондентов, они стали в этом успешны, по собственной оценке), 67 \% легко влились в режим работы школы, $62 \%$ нашли общий язык с родителями обучающихся, 58 \% были поддержаны коллегами и администрацией. При этом среди числа учителей, не имевших наставников, 12 \% испытывали трудности в организации учебной деятельности, 16 \% не находили взаимопонимания с коллегами, администрацией, учениками. Анализируя возможные причины возникших трудностей, 83 \% учителей-наставников называют отсутствие опыта, $42 \%$ - отсутствие грамотного наставника, $33 \%$ - условия, неблагоприятные для молодого специалиста в образовательном учреждении. В первые пять лет работы у 46 \% нынешних учителей-наставников возникало желание сменить профессию. По мнению 25 \% опрошенных, уровень подготовки в вузе не являлся причиной профессиональных затруднений, они оценили его как необходимый и достаточный.

Направленность педагогической деятельности на этапе ее становления в 67 \% случаев определялась интересами и особенностями детей, в $54 \%$ - имевшимся опытом, в $46 \%$ - опытом коллег. В сегодняшней работе эти, уже опытные и авторитетные, учителя прежде всего доверяют тем формам и методам, которые соответствуют запросам и возможностям учеников (79 \%), проверенным личным опытом (75 \%). При этом наименьшее влияние на работу в первые пять лет оказывали распоряжения администрации (12\%), инструктивные письма и приказы (8 \%). В настоящее время к рекомендациям лекторов и консультантов относятся настороженно 63 \%, к приемам и методам, описанным в методической литературе, - 58 \% респондентов. Таким образом, особенности учеников и личный опыт оказывают наибольшее влияние на педагогическую деятельность учителей-наставников на всем ее протяжении. Заслуживает внимания тот факт, что административные и методические указания воспринимаются молодыми учителями негативно, а опытными педагогами - как необходимая норма функционирования организации. К позитивным профессиональным качествам современных педагогов были отнесены коммуникативность (83\%), мобильность (79 \%), обучаемость (63\%). К негативным - авторитарность (79 \%), неумение/нежелание слышать других (54 \%), безразличное отношение к детям (50 \%).

Анкетирование педагогов-наставников позволяет определить ключевые, на взгляд авторов, показатели успешности в профессии:

- общение с детьми, желание работать учителем, общественная значимость профессии;

- периодом профессионального становления являются первые годы работы;

- отсутствие наставника является одной из важных причин возникновения профессиональных затруднений и заставляет задуматься о смене выбранной профессии;

- сформированность коммуникативных качеств, высокий уровень мобильности и обучаемости являются значимыми профессиональными качествами с точки зрения наставников.

В МБОУ «СОШ № 198» г. Северска культура наставничества формировалась все 25 лет ее функционирования, но межпоколенческий обмен знаниями и традициями в последние десятилетия значительно изменился. С изменением парадигмы образования, ростом числа и разнообразия стратегий школьного образования, развитием проектно-исследовательской деятельности, развитием возможностей электронных и сетевых ресурсов произошли перемены в моделях взаимодействия наставников и наставляемых.

Модель «один наставник - один наставляемый», пожалуй самая распространенная в педагогической практике, значительно разнообразилась: создан банк наставнических разработок, в котором молодые специалисты могут найти ответы на возникающие вопросы у нескольких наставников, появились дистанционные формы работы с молодыми педагогами, на собственных сайтах опытные учителя делают странички для начинающих коллег, 
размещая образцы рабочих программ, контрольно-измерительных материалов, памятки и таблицы к урокам и др.

Организуются наставнические группы, курирующие различные направления деятельности молодого специалиста: один наставник помогает решать вопросы учебной деятельности, другой - организацию внеурочных курсов, третий - проектную работу с учащимися.

Формы работы определяются запросами начинающих педагогов, сложившимися стилями взаимоотношений, характером решаемых педагогических задач. Ведущими формами работы наставников с молодыми педагогами в МБОУ «СОШ № 198» являются сопровождение и сотрудничество. В информационных технологиях, сетевых ресурсах молодые учителя могут оказывать помощь своим наставникам, в то время как они помогают в освоении содержания учебного предмета, методики его преподавания, организации учебного процесса. Такое взаимодействие уже можно назвать взаимообучением, меняющим ролевые позиции каждого из участников взаимодействия. В настоящее время наставники пробуют приемы коучинга - «персональной тренерской работы», тьюторства - «осуществления постоянной помощи взрослому, обучающемуся в решении вопросов организации обучения».

В группе наставников на уровне образовательной организации появилось понимание необходимости объединения в творческую группу, обучения по специализированным программам для наставников, обобщения и представления накопленного опыта, участия в конкурсах, проведения открытых обучающих мероприятий для муниципалитета и региона.

По мнению наставников, сегодняшних молодых педагогов отличают высокие амбиции, стремление к лидерству, достаточный уровень усвоения информации и критичности, высокий уровень социализированности в социальных сетях и недостаточный уровень социализированности в коллективе. Как и у многих учеников школы, потребность в наглядности у них несколько выше, чем потребность в осмыслении учебного материала.

Наставничество в современной школе занимает особое место: отношения «учитель ученик» издавна существовали во всех областях человеческой деятельности. Необходимость обучения наставников, сохранения в образовательных организациях культуры наставничества, разнообразия форм, технологий, методов, популяризации лучших практик становится ответом на вызовы времени. Поэтому наставничество - не просто модный тренд, а важная составляющая образовательной практики, развивающая и молодого педагога, и наставника, его сопровождающего.

\section{Список литературы}

1. Сарычева М. О. Механизмы развития наставничества в региональной системе общего образования Томской области: материалы круглого стола «Наставничество: лучшие практики». URL: http://rcro.tomsk.ru/2017/05/19/materialy-kruglogostola-nastavnichestvo-luchshie-praktiki (дата обращения: 19.05.2017).

2. Чеглакова Л. М., Сташенко А. Г. Наставничество: мода становится трендом // Корпоративные университеты. 2008. № 15. C. 37-49.

3. Круглова И. В. Наставничество как условие профессионального становления молодого учителя: авторефр. ... канд. пед. наук. М., 2007.

4. Зевунов А. В. Андрагогические основы построения системы обучения кадров на производстве // Совершенствование системы образования: материалы научного семинара молодых исследователей: сб. статей / сост. и ред. Г. А. Федотова, С. А. Александрова. Великий Новгород: НовГУ им. Ярослава Мудрого, 2009. С. 70-80.

5. Поздеева С. И. Особенности гуманитарного управления инновациями для становления профессионализма педагога начальной школы // Вестн. Томского гос. пед. ун-та (TSPU Bulletin). 2013. Вып. 9 (137). C. 194-196.

6. Поздеева С. И. Разработка концепции открытого профессионализма педагога как исследовательская задача // Вестн. Томского гос. пед. ун-та (TSPU Bulletin). 2016. Вып. 1 (166). С. 88-90.

7. Поздеева С. И. Инновационное развитие современной начальной школы: построение открытого совместного действия педагога и ребенка. Томск, 2013. 168 с. 
8. Анянова И. В. Коучинговые инструменты саморазвития и самооценки педагога в «накопительном саквояже» межаттестационного периода. URL: https://coachingineducation.ru/kouchingovye-instrumenty-samorazvitiya-i-samoocenkipedagoga-v-nakopitelnom-sakvoyazhe-mezhattestacionnogo-perioda/ (дата обращения: 24.05.2017).

9. Зырянова А. В. Организация тьюторского сопровождения в образовательном учреждении. URL: https://sites.google. com/site/tutorsoprovogdenie/tema-3-organizacia-tutorskogo-soprovozdenia-v-obrazovatelnom-ucrezdenii (дата обращения: 21.06.2017).

10. Булычева А. Е. Супервизия и/или методическое сопровождение в образовании. URL: http://www.supervis.ru/ content19072097-bulycheva-ae-superviziya-iili-metodicheskoe-soprovozhdenie-v-obrazovanii (дата обращения: 29.08.2017).

Кириллова Ирина Олеговна, учитель начальных классов, МБОУ «СОШ № 198» (ул. Победы, 12a, Северск, Томская обл., Россия, 636013). E-mail: kirillow71@sibmail.com

Материал поступил в редакцию 25.05.2017

DOI: $10.23951 / 2307-6127-2017-4-75-80$

\section{MENTORING: A POPULAR STREAM OR A CONSCIOUS NECESSITY?}

\section{O. Kirillova}

School no. 98, Seversk, Russian Federation

We examined the necessity to organize the work of teacher-mentors with young specialists and inexperienced teachers: attracting qualified personnel, transferring corporate culture, socialization in the professional community. We defined the concept of mentoring in an educational organization. We described the motivation of experienced teachers to engage in mentoring: recognition of authority, empowerment, financial support. We made an analysis of the questionnaires of teachers-mentors, which made it possible to identify the difficulties of teachers who do not have mentors at the beginning of work, have insufficient formation of mentor's competencies, they need special training for mentoring, support and evaluation. We defined key indicators of success in the profession: communication with children, the social importance of the profession; the first years of work are a significant period for becoming and consolidating in the profession; communicative, mobility and learning; the absence of a mentor is one of the important reasons for the emergence of professional difficulties. We described the directions of development and diversity of forms of mentoring activities in school: accompaniment of a young teacher by a single or a group of mentors, rendering assistance to mentors in any area of extracurricular, project, lesson activity, IT-mentoring, preparation for participation in a professional competitions, joint development and implementation by teachers-mentors of free educational events for young professionals and beginners teachers.

Key words: mentor, young teacher, choice of profession, professional formation, indicators of success, mentoring groups, cooperation, support, mutual learning.

\section{References}

1. Sarycheva M. O. Mekhanizmy razvitiya nastavnichestva v regional'noy sisteme obshchego obrazovaniya Tomskoy oblasti: materialy kruglogo stola "Nastavnichestvo: luchshiye praktiki" [Mechanisms of development of mentoring in the regional system of general education of Tomsk region": materials of the round table "Mentoring: best practices"] (in Russian). URL: http://rcro. tomsk.ru/2017/05/19/materialy-kruglogo-stola-nastavnichestvo-luchshie-praktiki/ (accessed 19 May 2017).

2. Cheglakova L. M., Stashenko A. G. Nastavnichestvo: moda stanovitsya trendom [Mentoring: fashion becomes a trend]. Korporativnyey universitety - Corporate Universitites, 2008, no. 15, pp. 37-49 (in Russian).

3. Kruglova I. V. Nastavnichestvo kak usloviye professional'nogo stanovleniya molodogo uchitelya. Avtoref. dis. kand. ped. nauk [Mentoring as a condition for the professional formation of a young teacher. Abstract of thesis cand. ped. sci.]. Moscow, 2007 (in Russian). 
4. Zevunov A. V. Andragogicheskiye osnovy postroyeniya sistemy obucheniya kadrov na proizvodstve [Adragogical bases of construction of system of training of personnel]. Sovershenstvovaniye sistemy obrazovaniya: materialy nauchnogo seminara molodykh issledovateley: sbornik statey. Sost. i red. G. A. Fedotova i S. A. Aleksandrova [Perfection of the education system: materials of the scientific seminar of young researchers: collection of articles. Comp. and ed. G. A. Fedotova, S. A. Alexandrova]. Velikiy Novgorod, Yaroslav-the-Wise Novgorod State University Publ., 2009. Pp. 70-80 (in Russian).

5. Pozdeeva S. I. Osobennosti gumanitarnogo upravleniya innovatsiyami dlya stanovleniya professionalizma pedagoga nachal'noy shkoly [The humanitarian features of innovation for the teacher competence formation at primary school]. Vestnik Tomskogo gosudarstvennogo pedagogicheskogo universiteta - TSPU Bulletin, 2013, vol. 9 (137), pp. 194-196 (in Russian).

6. Pozdeeva S. I. Razrabotka kontseptsii otkrytogo professionalizma pedagoga kak issledovatel'skaya zadacha [Development of the concept of open professionalism of a teacher as a research problem]. Vestnik Tomskogo gosudarstvennogo pedagogicheskogo universiteta - TSPU Bulletin, 2016, vol. 1 (166), pp. 88-90 (in Russian).

7. Pozdeeva S. I. Innovatsionnoye razvitiye sovremennoy nachal'noy shkoly: postroyeniye otkrytogo sovmestnogo deystviya pedagoga i rebenka [Innovative development of modern elementary school: creation of open joint action of a teacher and a child]. Tomsk, 2013. 168 p. (in Russian).

8. Anyanova I. V. Kouchingovyye instrumenty samorazvitiya i samootsenki pedagoga v "nakopitel'nom sakvoyazhe" mezhattestatsionnogo perioda [Coaching tools for self-development and teacher self-assessment in the "storage bag" of the inter-certification period] (in Russian). URL: https://coachingineducation.ru/kouchingovye-instrumenty-samorazvitiya-isamoocenki-pedagoga-v-nakopitelnom-sakvoyazhe-mezhattestacionnogo-periodal (accessed 24 May 2017).

9. Zyryanova A. V. Organizatsiya t'yutorskogo soprovozhdeniya v obrazovatel'nom uchrezhdenii [Organization of tutorship in an educational institution] (in Russian). URL: https://sites.google.com/site/tutorsoprovogdenie/tema-3-organizacia-tutorskogosoprovozdenia-v-obrazovatelnom-ucrezdenii (accessed 21 June 2017).

10. Bulycheva A. E. Superviziya i/lil metodicheskoye soprovozhdeniye v obrazovanii [Supervision and / or methodological support in education] (in Russian). URL: http://www.supervis.ru/content/19072097-bulycheva-ae-superviziya-iili-metodicheskoesoprovozhdenie-v-obrazovanii (accessed 29 August 2017).

Kirillova I. O., School no. 198 (ul. Pobedy, 12a, Seversk, Russian Federation, 636013). E-mail: kirillow71@sibmail.com 